\title{
Population responses within a landscape matrix: a macrophysiological approach to understanding climate change impacts
}

\author{
Steven L. Chown • Kevin J. Gaston • Mark van Kleunen • \\ Susana Clusella-Trullas
}

\begin{abstract}
Global environmental change (GEC) is a significant concern. However, forecasting the outcomes of this change for species and ecosystems remains a major challenge. In particular, predicting specific changes in systems where initial conditions, instabilities, and model errors have large impacts on the outcome is problematic. Indeed, predictive community ecology has been deemed unworthy of pursuit or an unreachable goal. However, new developments in large-scale biology provide ways of thinking that might substantially improve forecasts of local and regional impacts of climate change. Most notably, these are the explicit recognition of the regional and landscape contexts within which populations reside, the matrix approach that can be used to investigate the consequences of population variation across space and within assemblages, and the development of macrophysiology, which explicitly seeks to understand the ecological implications of physiological variation across large spatial and temporal scales. Here we explore how a combination of these approaches might promote further understanding and forecasting of the effects of global climate change and perhaps other GEC drivers on biodiversity. We focus on the population level, examining the ways in which environmental variation might be translated through performance and its plasticity to variation in demography.
\end{abstract}

Keywords Bioclimatic modelling - Mechanistic models $\cdot$ Performance curves · Phenotypic plasticity $\cdot r \times c$ matrices

\author{
S. L. Chown (凶) - S. Clusella-Trullas \\ Centre for Invasion Biology, Department of Botany and Zoology, Stellenbosch University, \\ Private Bag X1, 7602 Matieland, South Africa \\ e-mail: slchown@sun.ac.za \\ K. J. Gaston \\ Biodiversity and Macroecology Group, Department of Animal and Plant Sciences, \\ University of Sheffield, Sheffield S10 2TN, UK \\ M. van Kleunen \\ Institute of Plant Sciences and Oeschger Centre, University of Bern, \\ Altenbergrain 21, 3013 Bern, Switzerland
}




\section{Introduction}

Anthropogenic environmental change now numbers among the world's most pressing political and economic concerns. Whilst the likelihood and impacts of the major drivers of global environmental change (GEC) have long been the subject of disquiet (Arrhenius 1896; Huxley 1950; Hardin 1968), the direct implications for human welfare, and their indirect effects through alterations to biodiversity and ecosystem services have only recently risen to substantial political prominence (Gore 2006; Stern 2007). In all of these arenas it is not only the impacts of the GEC drivers that are of concern, but also the extent to which they are likely to be additive and, more importantly, synergistic (Brook 2008; Brook et al. 2008; Tylianakis et al. 2008). Climate change is of particular significance in this respect because it is likely to interact with all of the other GEC drivers.

Much research has now documented how climate change has acted either alone or in concert with other GEC drivers to affect biodiversity, and an increasing component of the field is concerned with predicting future impacts (reviews in Walther et al. 2002, 2005; Parmesan and Yohe 2003; Root et al. 2003; Parmesan 2006). Key messages from documented and forecast changes are that population extirpation will be ongoing, further species extinction is likely, and geographic ranges will continue to shift substantially and to be fragmented (see also Thomas et al. 2004, 2006; Pimm et al. 2006; Pounds et al. 2006). Moreover, the likelihood of particular outcomes will be contingent on the major climatic region being investigated, the extent of landscape fragmentation, and the life histories of the species concerned (Thomas et al. 2001, 2008; Stachowicz et al. 2002; Chown et al. 2007; Pörtner and Knust 2007; Theoharides and Dukes 2007; Deutsch et al. 2008).

In part, the challenge for biologists arises because it is exceptionally difficult to make predictions about the details of systems where initial conditions, instabilities, and model errors have large impacts on the outcome. The analogy may be drawn with predicting weather rather than climate, as made clear by Mahlman (1998: 91) in his pinball machine thought experiment. In this game, the path of the ball is unpredictable after a few collisions with the bumpers in the machine, although it is clear that at some point the ball will end in the gutter. However, the odds of the ball ending in the gutter can be altered dramatically by changing the slope of the playing field. In this latter scenario, the trajectory of the ball remains as unpredictable as before the change in slope, but the delay in the time to the ball reaching the gutter is predictable. So whilst the 'climate' has changed predictably, the 'weather' has remained as unpredictable as before (Mahlman 1998). In a similar vein, it has recently been shown that the context of change is likely to alter the direction and magnitude of global change effects on interactions among species (Tylianakis et al. 2008), so making precise ecological forecasting problematic. Nonetheless, broader forecasts of changes in geographic range limits and phenology are supported by current data (Parmesan 2006; Rosenzweig et al. 2008).

Part of the challenge is also associated with inadequacies of some the major methods currently used to investigate the forecast impacts of climate change, such as bioclimatic modelling. Both the utility of and problems associated with these models, and alternatives to them, are now being widely explored (e.g. Araújo et al. 2005; Elith et al. 2006; Austin et al. 2006; Austin 2007; Soberón 2007; Beale et al. 2008; Thuiller et al. 2008; Kearney and Porter 2009).

Fully addressing the forecasting challenge would appear almost to be arguing for the establishment of a predictive community ecology, a goal which seems either unworthy of pursuit at the community level (Ricklefs 2008) or simply unreachable (see discussion in Lawton 1999; Simberloff 2004). However, several recent advances in the field provide 
ways of thinking that might substantially improve forecasts of local and regional impacts of climate change and its interactions with other GEC drivers. Most notably, these are the explicit recognition of the regional and landscape contexts within which populations reside (Gaston and Blackburn 2000; Hubbell 2001; Leibold et al. 2004; Chase 2005; Ricklefs 2008), a matrix approach that can be used to investigate the consequences of population variation across space and within assemblages (Gaston 2002; Bell 2003; Gaston et al. 2008), and the development of macrophysiology, which explicitly seeks to understand the ecological implications of physiological variation across large spatial and temporal scales (Chown et al. 2004a; Osovitz and Hoffman 2007; Chown and Gaston 2008; Gaston et al. 2009). Here we explore how a combination of these approaches might promote further understanding and forecasting of the effects of global climate change and perhaps other GEC drivers on biodiversity. Before doing so, we briefly draw attention to the significance of forecast changes in water availability, and changes in the variation and predictability of particular climate variables, which may be as important as, or indeed in some cases more significant than, changes in mean temperature.

\section{The nature and form of change}

Although much of the focus on the impacts of climate change has been with changing temperature regimes and the seasonality of these changes (Harvell et al. 2002; Hansen et al. 2006; Parmesan 2006), for large areas of the globe changes in precipitation regimes and water stress will also be significant. What the ecological consequences will be more generally of precipitation change, such as the global change-type drought expected over many temperate to sub-tropical areas (Easterling et al. 2000; Breshears et al. 2005; Overpeck and Cole 2006; Stige et al. 2006), has not been extensively investigated, but they are likely to be significant (Tauber et al. 1998; Ciais et al. 2005; McGeoch et al. 2006; Staley et al. 2006; Chase 2007; Engelbrecht et al. 2007; Franks et al. 2007). For example, although the ultimate causes of amphibian declines in tropical Central America remain the subject of debate (e.g. Pounds et al. 1999, 2006; Rohr et al. 2008), changes in water availability owing to global temperature change and local habitat destruction are important (Rovito et al. 2009). In many areas of the world, species richness variation is strongly related to water availability (Hawkins et al. 2003; Chown et al. 2004b), suggesting that substantial declines in the numbers of species will accompany dwindling precipitation, though the identity of the species that remain behind may be affected by other factors (Algar et al. 2009). More subtle effects may also be associated with a change in the timing and predictability of rainfall (Lima et al. 1999; Holmgren et al. 2006; Foden et al. 2007; Tolley et al. 2008). Even changing wind regimes, as are being documented across large sectors of the Southern Ocean (Le Roux and McGeoch 2008; Turner et al. 2007), may affect the distributions and richness of species dependent on wind as an energy source, such as procellariiform seabirds (Jouventin and Weimerskirch 1990; Hashmi and Causey 2008; Davies et al. 2009).

From a population perspective, perhaps just as important as identifying the constituents of climate that are changing, is the fact that it is not only mean conditions that are involved, but also the frequency of extremes, the predictability and nature of more usual, and extreme, variation, and interactions among abiotic drivers (Gaines and Denny 1993; Gilchrist 1995; Brown and Brown 2000; Easterling et al. 2000; Helmuth et al. 2006; Chown and Terblanche 2007; Pulido 2007; Jentsch and Beierkuhnlein 2008; Parker et al. 2008; Welbergen et al. 2008; Pelini et al. 2009). The predictability of conditions (i.e. cue 
reliability) over various temporal and spatial scales is a key element determining whether phenotypic plasticity, one of two initial responses to environmental change (behavioural avoidance can be considered the other) is likely to be present or evolve in a population (Moran 1992; Tufto 2000; Sultan and Spencer 2002; Hazel et al. 2004; Gabriel 2005; Leimar 2009).

\section{The response to change in a focal population}

Within any given population, an environmental change might have a range of demographic effects. One particularly noteworthy, but relatively poorly addressed question is the magnitude of a change that is likely to trigger both a physiological effect and one that ultimately has a demographic outcome (Dunham et al. 1989; Porter 1989; Dillon et al. 2007). An alternative way of posing this question is to ask what the term 'given environment' means in the context, inter alia, of definitions such as that of beneficial acclimation (a form of plasticity), where acclimation to a given environment results in a performance advantage in that environment (Marais and Chown 2008), and under what conditions does acclimation affect individual performance in the field (Loeschcke and Hoffmann 2007; Kristensen et al. 2008). In other words, how large does a temperature change, for example, have to be to result in physiological and demographic responses. Nonetheless, assuming that an environmental change has effects that translate to a demographic level, these might result in emigration, decline (possibly to extinction), growth, or possibly a change in the dynamics of the population given that alterations in the intrinsic rate of increase can profoundly alter dynamics (May 1986; Gaston 2009).

The circumstances under which dispersal is selected for or against are the subject of a large literature and will not be examined in detail here (see McPeek and Holt 1992; Parvinen et al. 2003; Heinz et al. 2009). It is worth noting though that changes in dispersal ability and propensity can evolve rapidly (Cody and Overton 1996; Simmons and Thomas 2004), and may be more subtle than the presence of the physiological/morphological capability for dispersal might suggest (Moyle et al. 2009). Moreover, dispersal ability in a meta-population context has a considerable influence on the extent to which phenotypic plasticity, or alternatively ecotypes, might be expected in a local population (see below) so affecting short- and longer-term responses to change (Sultan and Spencer 2002).

At their most basic, changes in abundance reflect the ways in which alterations to environmental conditions are translated through individual responses, so altering survival probability and growth rate in the juvenile stage prior to reproduction, the probability and extent of reproduction, and, in iteroparous species, the timing of and survival between reproductive bouts (Sibly and Calow 1986; see also Dunham et al. 1989; Huey and Kingsolver 1989; Gilchrist 1995; Gaston 2009). One of the most straightforward ways to consider this translation of environmental conditions to alterations in survival or growth rates is in terms of response curves or performance curves (Huey and Kingsolver 1993; Chown and Gaston 2008). The variety in form of response curves is relatively small (Fig. 1), and they provide a clear illustration of the mechanistic relationship between the environment and some demographic parameter (or a trait closely related to such a parameter), which can be readily described mathematically (see e.g. Huey and Kingsolver 1989; David et al. 1997; de Jong 2005; Izem and Kingsolver 2005; Angilletta 2006). Although performance curves may legitimately be thought of as reaction norms (Angilletta et al. 2003), it is practically useful to consider them as the function linking one or more environmental variables to one or more demographic parameters; a function which in turn 



Fig. 1 The form of responses populations show to varying environmental factors. These might be (top left) logistic as in this temperature response curve; (top right) threshold, as in the survival response to low temperature in a species that can tolerate freezing up to $-11^{\circ} \mathrm{C}$; or (bottom left) asymptotic, as is frequently found in plants relative to a limiting nutrient. In (bottom right) a performance curve is shown. Redrawn from Chown and Gaston (2008)

may be fixed or phenotypically plastic, and may be subject to selection for changes in mean and variance (or the extent of plasticity; see also Lynch and Gabriel 1987; Gilchrist 1995; de Jong 2005; Ghalambor et al. 2007; Chown et al. 2008; Angilletta 2009).

Using a typical performance curve relating temperature and population growth rate, a response to change can readily be illustrated. If the optimum is relatively broad, and the environmental change small, little to no demographic effect is likely. The form of the curve itself is a function of both within and among generation variation in environmental conditions (Gilchrist 1995), so illustrating why changes in variance and their predictability are important. If the curve has a steeper form (see Angilletta 2009 for discussion of the evolution of shallow and steep response curves) and is fixed within a population (the latter might be the outcome either of environmental predictability or extreme unpredictability, see de Jong 2005; Deere and Chown 2006), then a relatively small increase in temperature might lead to a substantial decline in performance. Indeed, this is precisely the small thermal safety margin effect predicted for tropical ectotherms by Deutsch et al. (2008) owing to the asymmetric nature of performance curves, and the generally limited temperature acclimation capacity of tropical species compared to temperate ones. Many bioclimatic models assume such fixed response curves too, although rarely do they explore complex response curves (see discussion in Austin 2007; Chown and Gaston 2008). Curiously, few models also explore the longer-term population dynamic outcomes of changes in the intrinsic rate of increase, but simply assume that a change in climate translates directly into a change in presence/absence, and sometimes in abundance (but see Crozier and Dwyer 2006; Régnìere and Bentz 2007; Buckley 2008; Keith et al. 2008; Anderson et al. 2009). 
Alternatively, if the individuals within a population show phenotypic plasticity, and the environmental change is relatively slow, predictable, and long-lasting (by comparison with longevity of individuals, and in multi-stage species, one or more of their stages), then some form of short-term demographic response might take place. The timing of avian migration to a site provides an appropriate example (Gienapp et al. 2008). The plasticity that is characteristic of individuals within a population can take on several forms (Huey et al. 1999; Deere and Chown 2006; Angilletta 2009), though they do constitute something of a continuum, and will depend also on the trait in question (see e.g. Liefting et al. 2009), life stage and its duration, and the behavioural flexibility of the species. For example, in the sub-Antarctic kelp fly Paractora dreuxi, upper and lower lethal limits show no significant phenotypic plasticity in adults and larvae (Marais et al. 2009). By contrast, chill coma recovery shows beneficial acclimation in larvae, whereas adults perform best after being exposed to low temperatures (Marais and Chown 2008). Nonetheless, the relationship between phenotypic changes in populations (for examples of population variation in plasticity see e.g. Liefting and Ellers 2008; Liefting et al. 2009; Orizaola and Laurila 2009), which may be rapid under anthropogenic environmental change, and alterations in the probability of persistence or establishment remain poorly investigated (see Hendry et al. 2008).

If an alteration in performance curve does take place, then it may well be that little demographic effect is realized, or that it is exacerbated relative to the situation of no change. Moreover, some acclimation responses have substantial physiological penalties such that although one trait (e.g. survival) may show no change, another (such as performance) might be markedly affected (see discussion in Hoffmann 1995; Feder and Hofmann 1999). Although the costs of plasticity form an important component of models for understanding the conditions under which plasticity might evolve (van Tienderen 1991; Sultan and Spencer 2002; Masel et al. 2007), studies thereof are only now starting to accumulate (Relyea 2002; van Kleunen and Fischer 2005, 2007; Kristensen et al. 2008).

Over several generations, selection for changes in the mean trait values or their plasticity may also take place (see discussion in Gilchrist 1995). Recent work has shown that genetic changes in populations are taking place in response to climate change. In many species these have to do with shifts in phenology (Bradshaw and Holzapfel 2006, 2008), and evolutionary change in response to climate fluctuations may be rapid (Pulido and Berthold 2004; Franks et al. 2007), though apparently not always fast enough to keep up with the rate of climate change (Etterson and Shaw 2001). Nonetheless, much of the phenotypic change that has been documented as a response to anthropogenic change may be due more to phenotypic plasticity than to evolutionary changes of trait means (Gienapp et al. 2007, 2008; Pulido 2007; Hendry et al. 2008).

\section{Populations in a regional context}

Although the extent of plasticity, its form and its demographic effects may seem, from the above discussion, to be entirely contingent, several, relatively consistent, broader patterns have long been noted, and increasingly the evidence seems to support them. For example, physiological plasticity is likely to be reduced in the presence of behavioural flexibility (Marais and Chown 2008; see also Huey et al. 2003), tropical species tend to show reduced plasticity by comparison with their temperate counterparts (Ghalambor et al. 2006), tropical and marine polar stenotherms show much less plasticity than do temperate eurytherms (Pörtner 2002), and species with considerable basal tolerance may have reduced

plasticity (Gause 1942; Stillman 2003). 
At a more local level, the extent of plasticity, and the likelihood that this may change through time, depends on the regional context of the population, and notably the extent of dispersal among patches differing in quality (Sultan and Spencer 2002; Hazel et al. 2004; Leimar 2009). This local dependency on regional circumstances is well reflected in Ricklefs' (2008: 746) remark that the 'presence and relative abundance of a species at a particular point might depend on interactions with populations that do not occur there'. Perhaps unsurprisingly, the extent of dispersal among patches also plays a role in determining the likelihood that a population will evolve to overcome a particular environmental constraint (Kirkpatrick and Barton 1997; Holt and Keitt 2005; Alleaume-Benharira et al. 2006; Goldberg and Lande 2007). Interactions among metapopulations may promote or retard adaptation to a given environment, influenced also by the temporal autocorrelation structure of the environmental change (Holt et al. 2004).

In the context of climate change, the obvious question is the extent to which phenotypic plasticity might promote or retard changes in geographic ranges associated with changing local conditions (Chown and Terblanche 2007; see also Gienapp et al. 2007, 2008; Hendry et al. 2008). At least part of the answer to this question depends on the way in which phenotypic plasticity is viewed in the context of evolutionary change (discussed at length in de Jong 2005). Nonetheless, a range of outcomes is possible, and these have been most recently, and clearly, set out by Ghalambor et al. (2007). First, adaptive plasticity might produce a phenotype that is close to optimal under the new environmental conditions. In this case, little demographic change in the population would take place, and the population would not evolve owing to the absence of directional selection. Second, adaptive plasticity might produce a phenotype that goes some way towards reaching the local optimum, but will be sufficiently distant for strong directional selection to take place. Initially, a demographic change will occur, but this may be reversed following several generations of selection. Third, plasticity might be non-adaptive, and carry a phenotype away from the local optimum. Here extinction is very likely and such non-adaptive plasticity is likely to be common (van Kleunen and Fischer 2005). Finally, environmental stress might increase trait variance to such an extent that some variant is able to cross an adaptive valley and find a new local optimum. In the first two cases the least alteration in range sizes and positions is expected with climate change, whereas in the latter cases substantial range shifts might be expected. Of course, the nature of the change is dependent also on how plasticity arose in the past in a given population, and the extent to which it is constrained by dispersal from other populations. Intermediate levels of dispersal may well facilitate crossing to a new local optimum by promoting plasticity, but may also leave scope for directional selection (see related discussion in de Jong 2005; Ghalambor et al. 2007: 402). However, further to complicate matters, the extent to which phenotypic change is possible is likely to be limited by the presence of other species (de Mazancourt et al. 2008). This idea has so far been explored only for evolutionary change in trait means among patches and not for how plasticity might influence this evolution or how species and patch diversity might influence plasticity. Nonetheless, an important conclusion of de Mazancourt et al.'s (2008) study is that under many circumstances phenotypes are less likely to change than are abundances.

\section{Scaling up}

Local population responses, though potentially complex, can readily be scaled up by considering them in the context of species by sites (rows by columns, $r \times c$ ) matrices (Fig. 2a). Indeed, such matrices, which can be further resolved into several spatial 


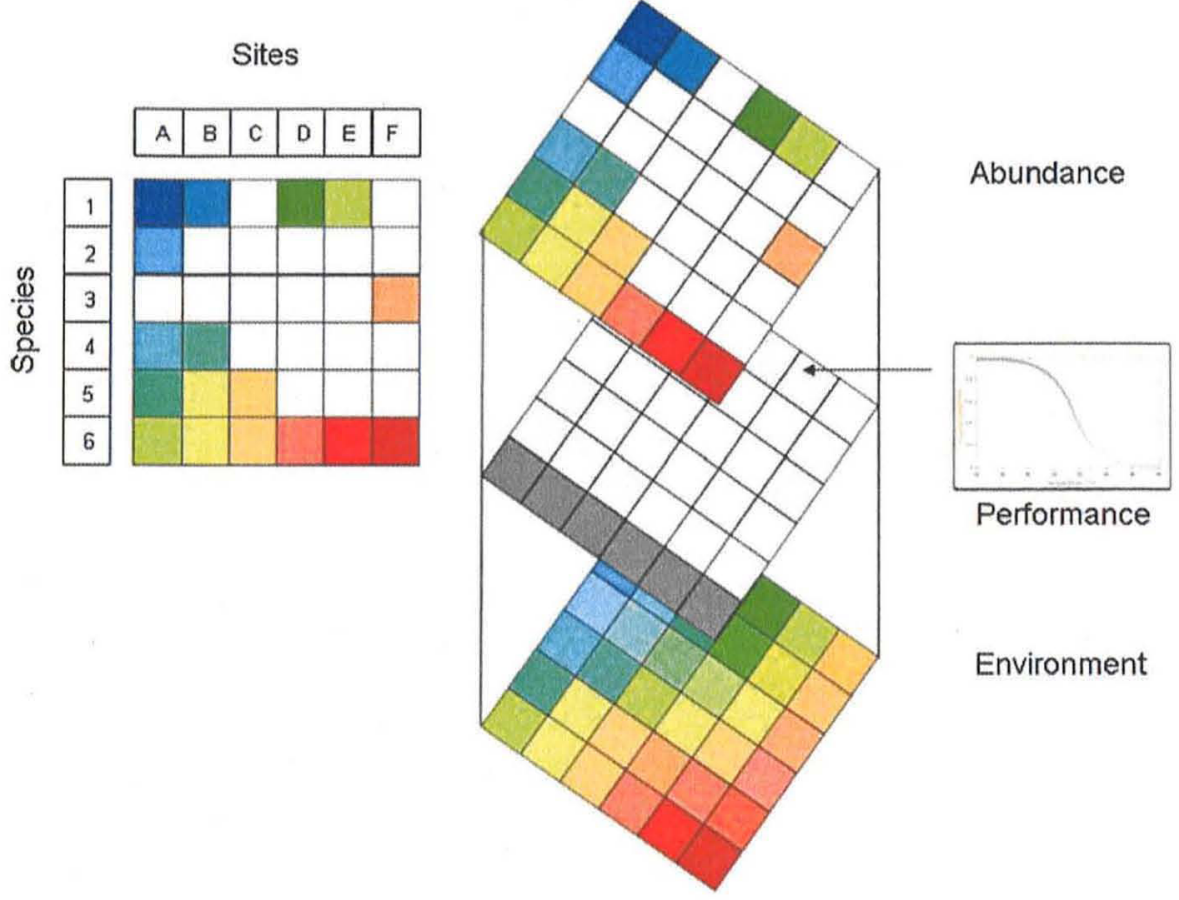

Fig. 2 Left: A typical $r \times c$, species $x$ sites matrix. The colours can be interpreted as variation in any characteristics, such as abundance, body size, birth rate, desiccation resistance, lower lethal temperature or development rate. White squares indicate that the species does not occur at that site. Right: The matrix can be thought of either exactly as in the left-hand panel, with environmental variation giving rise, through either a spatially stable or spatially variable performance curve, to variation in a characteristic such as abundance. Alternatively, the matrix can be seen as a spatially expanded one. The $x$ and $y$ coordinates provide the explicit spatial position in the landscape, again with the environment being translated by the organism into some form of variation in other traits, although responses might also reduce the extent to which environmental variation is realized in some characteristic. In models of the kind being developed by Kearney and Porter (2009) several parameters are included in the intermediate layers. The mean trait value and mean spatial position then serve as inputs to the $r \times c$ matrix. Formal statistics for relating such matrices are also provided by Dray and Legendre (2008)

dimensions (Fig. 2b), may be the key to relating local population mechanisms and patterns to those that emerge at the interspecific and assemblage levels (Dray and Legendre 2008; Gaston et al. 2008). Traditionally, cells of such a matrix would comprise the presences/ absences of species or their respective abundances at a series of sites (e.g. Gaston 2002; Bell 2003). However, the matrix can be populated with virtually any parameter (e.g. Fig. 3), such as the resting metabolic rate or critical thermal minimum of a series of populations (see e.g. Klok and Chown 2003; Wikelski et al. 2003 for these kinds of data). Moreover, in the spatially explicit form, spatial variation in an environmental parameter (e.g. mean growing season temperature) might form the first matrix, and, with an appropriate function relating the environmental parameter to survival of growth rate, this might be translated into predicted abundance. The function matrix could be considered invariant across space, time and/or taxonomy (niche conservatism-see Wiens and Graham 2005), or some form of nonstationarity (used in the geostatistical sense, see Foody 2004) could be introduced. The spatial variation might reflect realized or predicted phenotypic plasticity, 


\begin{tabular}{|c|c|c|c|c|c|c|}
\hline $\begin{array}{l}i \text { Species / } j \\
\text { Sites }\end{array}$ & $\begin{array}{l}\text { Site A } \\
\left(40^{\circ} \mathrm{S}\right)\end{array}$ & $\begin{array}{l}\text { Site B } \\
\left(38^{\circ} \mathrm{S}\right)\end{array}$ & $\begin{array}{l}\text { Site C } \\
\left(35^{\circ} \mathrm{S}\right)\end{array}$ & $\begin{array}{l}\text { Site D } \\
\left(30^{\circ} \mathrm{S}\right)\end{array}$ & $\begin{array}{c}\text { Mean } \\
\text { CTmin }\left({ }^{\circ} \mathrm{C}\right)\end{array}$ & $\begin{array}{c}\text { Mean latitude } \\
\left({ }^{\circ} \mathrm{S}\right)\end{array}$ \\
\hline Sp. 1 & 4.0 & 5.0 & 6.0 & 8.0 & 5.8 & 35.8 \\
\hline Sp. 2 & 3.0 & 4.0 & 7.0 & & 4.7 & 37.7 \\
\hline Sp. 3 & 3.0 & 4.0 & & & 3.5 & 39.0 \\
\hline Sp. 4 & 2.0 & & & & 2.0 & 40.0 \\
\hline $\begin{array}{l}\text { Mean CTmin } \\
\left({ }^{\circ} \mathrm{C}\right)\end{array}$ & 3.0 & 4.3 & 6.5 & 8.0 & & \\
\hline Variance & 0.7 & 0.3 & & & & \\
\hline
\end{tabular}

Fig. 3 A matrix of species ( $i$ ) by sites $(j)$ indicating how physiological variables may be included in such a matrix and can provide insight into intraspecific, interspecific and assemblage-level variation. The variable is critical thermal minimum (CTmin, see Chown and Terblanche 2007). The red rectangle indicates intraspecific variation across space. Interspecific variation (green) is calculated as a mean value for the species at the centre of their latitudinal range, whilst assemblage characteristics are the mean and variance a trait across all species at a given site (blue; redrawn from Chown \& McGeoch, in review) (Color figure online)

or ecotypic variation, in turn associated with a matrix containing realized or predicted connection strength (dispersal) among populations. Likewise, a realized abundance matrix could be subject to the effects of interactions with other species based on what might be expected from interaction strengths or other food web parameters (see e.g. Berlow et al. 2004), or to the effects of a regional source pool. Formal mathematical approaches for investigating the relationships among matrices and for testing the significance of the parameters of the associations are available (see. Legendre et al. 1997; Dray and Legendre 2008). Likewise, characteristics of matrices, such as nestedness, can be analyzed to assess the roles various factors play in structuring assemblages (e.g. Azeria and Kolasa 2008; see also Chown 1993; Worthen et al. 1998 for examples of how desiccation resistance might influence assemblage structure).

At their most straightforward, a spatially explicit set of matrices amount to bottom-up modelling of the kind increasingly being used to understand the ways in which environmental variation translates into abundance/distribution (Kearney 2006; Kearney and Porter 2009). Such approaches have long been used to investigate crop plant performance (see e.g. Whisler et al. 1986; Brisson et al. 1992), and indeed have been scaled up to higher levels to understand richness variation and biome distributions across the planet (Kleidon and Mooney 2000; Bond et al. 2005). More recently, they have also started to be used to explore habitat preferences and abundances at a variety of spatial scales in animals (Kearney and Porter 2004; Helmuth et al. 2005, 2006; Crozier and Dwyer 2006; Buckley 2008; Kearney et al. 2008), and to understand the link between species traits and environments (Legendre et al. 1997; Dray and Legendre 2008). Not only can they incorporate subtle variation in the environment (such as changes in the predictability of conditions; Porter et al. 2000), but they can also include spatially varying physiological responses, and responses to other species. Moreover, these responses can be allowed to vary in ways that might be predicted by within- and between generation responses to various forms of environmental change, so allowing evolutionary dynamics to be included into the models (Kearney et al. 2009).

Bioclimatic approaches adopt various methods to resolve the function relating abundance or presence/absence to several environmental matrices, often neglecting the physiological, dispersal, evolutionary, and biotic interaction components of the function. As Kearney (2006) has noted, combining top-down and bottom-up approaches improves 
understanding of the likelihood to which either historical factors or biotic interactions might be responsible for present distributions. Moreover, environmental matrices can also be used to predict species richness, either by using empirically derived relationships (O'Brien et al. 2000; Kalmar and Currie 2007) or theoretical expectations (Allen et al. 2002). Concatenation of the spatially explicit population-level matrices can be compared with the predicted matrices to provide further insight into how climate change might actually translate into assemblage level change. Indeed, a variation of such an approach has been used to understand how spatial variation in common species might be responsible for much of the variation seen in species richness at large spatial scales (Šizling et al. 2009). Alternatively, both sets of data can be re-expressed more simply as $r \times c$ matrices to provide insights into likely morphological and functional change (Gaston et al. 2008, submitted manuscript).

\section{Conclusions}

Forecasts of the effects of climate change and other GEC drivers on biodiversity are likely to be most significant at two levels. First, the fates of individual species are likely to remain a concern for both conservation and control reasons, and will encompass the likelihood of these species shifting along the rare-common axis (both in abundance and range; see Gaston 1999). Second, maintaining the efficacy of large areas for ecosystem service delivery is growing as a conservation priority (Millennium Ecosystem Assessment 2005). In both cases, effective empirical and theoretical means for understanding GEC impacts are being developed. The $r \times c$ matrices discussed here are especially noteworthy because they provide a way of moving between all levels in the biological hierarchy, recognizing that the higher ones are emergent from the population level, but also feed back to influence it. They do not resolve the difficulty of understanding and predicting complex systems where initial conditions, instabilities in the system, and model errors have large impacts on the outcome. Nonetheless, they do suggest that ways may be found to couple broad-brush generalizations with the specifics of particular populations. For example, a growing number of modelling studies are demonstrating that assemblage level characteristics can be derived from patterns of aggregation at multiple spatial scales (e.g. Hui et al. 2006; Storch et al. 2008). At several of these scales, aggregation is dependent on the autocorrelation structure of the environment and the way in which this translates through individual responses to aggregation —or the spatial autocorrelation —of abundance.

Acknowledgments We thank Mike Angilletta, Jen Lee, John Terblanche and an anonymous referee for comments on a previous version of this manuscript. This work was partially supported by NRF Grant IFR2008071500012 to SLC and partially by a Stellenbosch University Overarching Strategic Plan grant.

\section{References}

Algar AC, Kerr JT, Currie DJ (2009) Evolutionary constraints on regional faunas: whom, but not how many. Ecol Lett 12:57-65

Alleaume-Benharira M, Pen IR, Ronce O (2006) Geographical patterns of adaptation within a species' range: interactions between drift and gene flow. J Evol Biol 19:203-215

Allen AP, Brown JH, Gillooly JF (2002) Global biodiversity, biochemical kinetics, and the energeticequivalence rule. Science 297:1545-1548

Anderson BJ, Akçakaya HR, Araújo MB, Fordham DA, Martinez-Meyer E, Thuiller W, Brook BW (2009)

Dynamics of range margins for metapopulations under climate change. Proc R Soc Lond 276: 1415-1420 
Angilletta MJ (2006) Estimating and comparing thermal performance curves. J Therm Biol 31:541-545 Angilletta MJ (2009) Thermal adaptation. A theoretical and empirical synthesis. Oxford University Press, Oxford

Angilletta MJ, Wilson RS, Navas CA, James RS (2003) Tradeoffs and the evolution of thermal reaction norms. Trends Ecol Evol 18:234-240

Araújo MB, Whittaker RJ, Ladle RJ et al (2005) Reducing uncertainty in projections of extinction risk from climate change. Global Ecol Biogeogr 14:529-538

Arrhenius S (1896) On the influence of carbonic acid in the air upon the temperature of the ground. Philos Mag J Sci 4:237-276

Austin M (2007) Species distribution models and ecological theory: a critical assessment and some possible new approaches. Ecol Model 200:1-19

Austin MP, Belbin L, Meyers JA et al (2006) Evaluation of statistical models used for predicting plant species distributions: role of artificial data and theory. Ecol Modell 199:197-216

Azeria ET, Kolasa J (2008) Nestedness, niche metrics and temporal dynamics of a metacommunity in a dynamic natural model system. Oikos 117:1006-1019

Beale CM, Lennon JJ, Gimona A (2008) Opening the climate envelope reveals no macroscale associations with climate in European birds. Proc Natl Acad Sci USA 105:14908-14912

Bell G (2003) The interpretation of biological surveys. Proc R Soc Lond B 270:2531-2542

Berlow EL, Neutel AM, Cohen JE et al (2004) Interaction strengths in food webs: issues and opportunities. J Animal Ecol 73:585-598

Bond WJ, Woodward FI, Midgley GF (2005) The global distribution of ecosystems in a world without fire. New Phytol 165:525-537

Bradshaw WE, Holzapfel CM (2006) Evolutionary response to rapid climate change. Science 312: $1477-1478$

Bradshaw WE, Holzapfel CM (2008) Genetic responses to rapid climate change: it's seasonal timing that matters. Mol Ecol 17:157-166

Breshears DD, Cobb NS, Rich PM et al (2005) Regional vegetation die-off in response to global-changetype drought. Proc Natl Acad Sci USA 102:15144-15148

Brisson N, Sguin B, Bertuzzi P (1992) Agrometeorological soil-water balance for crop simulation-models. Agric Forest Meteorol 59:267-287

Brook BW (2008) Synergies between climate change, extinctions and invasive invertebrates. Wildl Res 35:249-252

Brook BW, Sodhi NS, Bradshaw CJA (2008) Synergies among extinction drivers and global change. Trends Ecol Evol 23:453-460

Brown CR, Brown MB (2000) Weather-mediated natural selection on arrival time in cliff swallows (Petrochelidon pyrrhonota). Behav Ecol Sociobiol 47:339-345

Buckley LB (2008) Linking traits to energetics and population dynamics to predict lizard ranges in changing environments. Am Nat 171:E1-E19

Chase JM (2005) Towards a really unified theory for metacommunities. Funct Ecol 19:182-186

Chase JM (2007) Drought mediates the importance of stochastic community assembly. Proc Natl Acad Sci USA 104:17430-17434

Chown SL (1993) Desiccation resistance in six sub-Antarctic weevils (Coleoptera: Curculionidae): humidity as an abiotic factor influencing assemblage structure. Funct Ecol 7:318-325

Chown SL, Gaston KJ (2008) Macrophysiology for a changing world. Proc R Soc Lond B 275:1469-1478

Chown SL, Terblanche JS (2007) Physiological diversity in insects: ecological and evolutionary contexts. Adv Insect Physiol 33:50-152

Chown SL, Gaston KJ, Robinson D (2004a) Macrophysiology: large-scale patterns in physiological traits and their ecological implications. Funct Ecol 18:159-167

Chown SL, Sinclair BJ, Leinaas HP et al (2004b) Hemispheric asymmetries in biodiversity - a serious matter for ecology. PLoS Biol 2:1701-1707

Chown SL, Slabber S, McGeoch MA et al (2007) Phenotypic plasticity mediates climate change responses among invasive and indigenous arthropods. Proc R Soc London B 274:2661-2667

Chown SL, Sørensen JG, Sinclair BJ (2008) Physiological variation and phenotypic plasticity: a response to 'Plasticity in arthropod cryotypes' by Hawes and Bale. J Exp Biol 211:3353-3357

Ciais P, Reichstein M, Viovy N et al (2005) Europe-wide reduction in primary productivity caused by the heat and drought in 2003. Nature 437:529-533

Cody ML, Overton JM (1996) Short-term evolution of reduced dispersal in island plant populations. J Ecol 84:53-61

Crozier L, Dwyer G (2006) Combining population-dynamic and ecophysiological models to predict climateinduced insect range shifts. Am Nat 167:853-866 
David JR, Gibert P, Gravot E et al (1997) Phenotypic plasticity and developmental temperature in Drosophila: analysis and significance of reaction norms of morphometrical traits. J Therm Biol 22:441-451

Davies RG, Irlich UM, Chown SL, Gaston KJ (2009) Energy and ocean availability predict latitudinal asymmetry in global species richness of procellariiform seabirds. Global Ecol Biogeogr (in press)

de Jong G (2005) Evolution of phenotypic plasticity: patterns of plasticity and the emergence of ecotypes. New Phytol 166:101-118

de Mazancourt C, Johnson E, Barraclough TG (2008) Biodiversity inhibits species' evolutionary responses to changing environments. Ecol Lett 11:380-388

Deere JA, Chown SL (2006) Testing the beneficial acclimation hypothesis and its alternatives for locomotor performance. Am Nat 168:630-644

Deutsch CA, Tewksbury JJ, Huey RB et al (2008) Impacts of climate warming on terrestrial ectotherms across latitude. Proc Natl Acad Sci USA 105:6668-6672

Dillon ME, Cahn LRY, Huey RB (2007) Life history consequences of temperature transients in Drosophila melanogaster. J Exp Biol 210:2897-2904

Dray S, Legendre P (2008) Testing the species traits-environment relationships: the fourth-corner problem revisited. Ecology 89:3400-3412

Dunham AE, Grant BW, Overall KL (1989) Interfaces between biophysical and physiological ecology and the population ecology of terrestrial vertebrate ectotherms. Physiol Zool 62:335-355

Easterling DR, Meehl GA, Parmesan C et al (2000) Climate extremes: observations, modeling, and impacts. Science 289:2068-2074

Elith J, Graham CH, Anderson RP et al (2006) Novel methods improve prediction of species' distributions from occurrence data. Ecography 29:129-151

Engelbrecht BMJ, Comita LS, Condit R et al (2007) Drought sensitivity shapes species distribution patterns in tropical forests. Nature $447: 80-82$

Etterson JR, Shaw RG (2001) Constraint to adaptive evolution in response to global warming. Science 294:151-154

Feder ME, Hofmann GE (1999) Heat-shock proteins, molecular chaperones, and the stress response: evolutionary and ecological physiology. Ann Rev Physiol 61:243-282

Foden W, Midgley GF, Hughes G et al (2007) A changing climate is eroding the geographical range of the Namib Desert tree Aloe through population declines and dispersal lags. Divers Distrib 13: $645-653$

Foody GM (2004) Spatial nonstationarity and scale-dependency in the relationship between species richness and environmental determinants for the sub-Saharan endemic avifauna. Global Ecol Biogeogr 13: 315-320

Franks SJ, Sim S, Weis AE (2007) Rapid evolution of flowering time by an annual plant in response to a climate fluctuation. Proc Natl Acad Sci USA 104:1278-1282

Gabriel W (2005) How stress selects for reversible phenotypic plasticity. J Evol Biol 18:873-883

Gaines SD, Denny MW (1993) The largest, smallest, highest, lowest, longest, and shortest: extremes in ecology. Ecology 74:1677-1692

Gaston KJ (1999) Implications of interspecific and intraspecific abundance-occupancy relationships. Oikos 86:195-207

Gaston KJ (2002) Abundance, occupancy and conservation biology. In: Chamberlain DE, Wilson AM (eds) Avian landscape ecology: pure and applied issues in the large-scale ecology of birds. Proceedings of the 2002 IALE(UK) conference. IALE(UK). Garstang, Lancs, pp 215-227

Gaston KJ (2009) Geographic range limits: achieving synthesis. Proc R Soc Lond B 276:1395-1406

Gaston KJ, Blackburn TM (2000) Pattern and process in macroecology. Blackwell Science, Oxford

Gaston KJ, Chown SL, Evans KL (2008) Ecogeographical rules: elements of a synthesis. J Biogeogr 35:483-500

Gaston KJ, Chown SL, Calosi P et al (2009) Macrophysiology: a conceptual re-unification. Am Nat 174:595-612

Gause GF (1942) The relation of adaptability to adaptation. Quart Rev Biol 17:99-114

Ghalambor CK, Huey RB, Martin PR et al (2006) Are mountain passes higher in the tropics? Janzen's hypothesis revisited. Integr Comp Biol 46:5-17

Ghalambor CK, McKay JK, Carroll SP et al (2007) Adaptive versus non-adaptive phenotypic plasticity and the potential for contemporary adaptation in new environments. Funct Ecol 21:394-407

Gienapp P, Leimu R, Merilä J (2007) Responses to climate change in avian migration time-microevolution versus phenotypic plasticity. Clim Res 35:25-35

Gienapp P, Teplitsky C, Alho JS et al (2008) Climate change and evolution: disentangling environmental and genetic responses. Mol Ecol 17:167-178 
Gilchrist GW (1995) Specialists and generalists in changing environments. I. Fitness landscapes of thermal sensitivity. Am Nat 146:252-270

Goldberg EE, Lande RL (2007) Species' borders and dispersal barriers. Am Nat 170:297-304

Gore A (2006) An inconvenient truth. The planetary emergency of global warming and what we can do about it. Bloomsbury, London

Hansen J, Sato M, Ruedy R et al (2006) Global temperature change. Proc Natl Acad Sci USA 103: $14288-14293$

Hardin G (1968) The tragedy of the commons. Science 162:1243-1248

Harvell CD, Mitchell CE, Ward JR et al (2002) Climate warming and disease risks for terrestrial and marine biota. Science 296:2158-2162

Hashmi D, Causey D (2008) A system in which available energy per se controls alpha diversity: marine pelagic birds. Am Nat 171:419-429

Hawkins BA, Field R, Cornell HV et al (2003) Energy, water, and broad-scale geographic patterns of species richness. Ecology 84:3105-3117

Hazel W, Smock R, Lively CM (2004) The ecological genetics of conditional strategies. Am Nat 163: $888-900$

Heinz SK, Mazzucco R, Dieckmann U (2009) Speciation and the evolution of dispersal along environmental gradients. Evol Ecol 23:53-70

Helmuth B, Kingsolver JG, Carrington E (2005) Biophysics, physiological ecology, and climate change: does mechanism matter? Ann Rev Physiol 67:177-201

Helmuth B, Mieszkowska N, Moore P et al (2006) Living on the edge of two changing worlds: forecasting the responses of rocky intertidal ecosystems to climate change. Annu Rev Ecol Evol Syst 37:373-404

Hendry AP, Farrugia TJ, Kinnison MT (2008) Human influences on rates of phenotypic change in wild populations. Mol Ecol 17:20-29

Hoffmann AA (1995) Acclimation: increasing survival at a cost. Trends Ecol Evol 10:1-2

Holmgren M, López BC, Gutierréz JR et al (2006) Herbivory and plant growth rate determine the success of El Niño Southern Oscillation-driven tree establishment in semiarid South America. Global Change Biol 12:2263-2271

Holt RD, Keitt TH (2005) Species' borders: a unifying theme in ecology. Oikos 108:3-6

Holt RD, Barfield M, Gomulkiewicz R (2004) Temporal variation can facilitate niche evolution in harsh sink environments. Am Nat 164:187-200

Hubbell SP (2001) The unified theory of biodiversity and biogeography. Princeton University Press, Princeton

Huey RB, Kingsolver JG (1989) Evolution of thermal sensitivity of ectotherm performance. Trends Ecol Evol 4:131-135

Huey RB, Kingsolver JG (1993) Evolution of resistance to high temperature in ectotherms. Am Nat 142:S21-S46

Huey RB, Berrigan D, Gilchrist GW et al (1999) Testing the adaptive significance of acclimation: a strong inference approach. Am Zool 39:323-336

Huey RB, Hertz PE, Sinervo B (2003) Behavioral drive versus behavioral inertia in evolution: a null model approach. Am Nat 161:357-366

Hui C, McGeoch MA, Warren M (2006) A spatially explicit approach to estimating species occupancy and spatial correlation. J Animal Ecol 75:140-147

Huxley A (1950) Themes and variations. Chatto and Windus, London

Izem R, Kingsolver JG (2005) Variation in continuous reaction norms: quantifying directions of biological interest. Am Nat 166:277-289

Jentsch A, Beierkuhnlein C (2008) Research frontiers in climate change: effects of extreme meteorological events on ecosystems. C.R. Geoscience 340:621-628

Jouventin P, Weimerskirch H (1990) Satellite tracking of Wandering albatrosses. Nature 343:746-748

Kalmar A, Currie DJ (2007) A unified model of avian species richness on islands and continents. Ecology $88: 1309-1321$

Kearney M (2006) Habitat, environment and niche: what are we modelling? Oikos 115:186-191

Kearney M, Porter WP (2004) Mapping the fundamental niche: physiology, climate, and the distribution of a nocturnal lizard. Ecology 85:3119-3131

Kearney M, Porter WP (2009) Mechanistic niche modelling: combining physiological and spatial data to predict species' ranges. Ecol Lett 12:334-350

Kearney M, Phillips BL, Tracy CR et al (2008) Modelling species distributions without using species distributions: the cane toad in Australia under current and future climates. Ecography 31 : $423-434$ 
Kearney M, Porter WP, Williams C et al (2009) Integrating biophysical models and evolutionary theory to predict climate impacts on species' ranges: the dengue mosquito Aedes aegypti in Australia. Funct Ecol 23:528-538

Keith DA, Akçakaya HR, Thuiller W (2008) Predicting extinction risks under climate change: coupling stochastic population models with dynamic bioclimatic habitats models. Biol Lett 4:560-563

Kirkpatrick M, Barton NH (1997) Evolution of a species' range. Am Nat 150:1-23

Kleidon A, Mooney HA (2000) A global distribution of biodiversity inferred from climatic constraints: results from a process-based modelling study. Global Change Biol 6:507-523

Klok CJ, Chown SL (2003) Resistance to temperature extremes in sub-Antarctic weevils: interspecific variation, population differentiation and acclimation. Biol J Linn Soc 78:401-414

Kristensen TN, Hoffmann AA, Overgaard J et al (2008) Costs and benefits of cold acclimation in fieldreleased Drosophila. Proc Natl Acad Sci USA 105:216-221

Lawton JH (1999) Are there general laws in ecology? Oikos 84:177-192

Le Roux PC, McGeoch MA (2008) Changes in climate extremes, variability and signature on sub-Antarctic Marion Island. Climatic Change 86:309-329

Legendre P, Galzin R, Harmelin-Vivien ML (1997) Relating behaviour to habitat: solutions to the fourthcorner problem. Ecology 78:547-562

Leibold MA, Holyoak M, Mouquet N et al (2004) The metacommunity concept: a framework for multi-scale community ecology. Ecol Lett 7:601-613

Leimar O (2009) Environmental and genetic cues in the evolution of phenotypic polymorphism. Evol Ecol 23:125-135

Liefting M, Ellers J (2008) Habitat specific differences in thermal plasticity in natural populations of a soil arthropod. Biol J Linn Soc 94:265-271

Liefting M, Hoffmann AA, Ellers J (2009) Plasticity versus environmental canalization: population differences in thermal responses along a latitudinal gradient in Drosophila serrata. Evolution 63: 1954-1963

Lima M, Keymer JE, Jaksic FM (1999) El Niño-Southern oscillation-driven rainfall variability and delayed density dependence cause rodent outbreaks in western South America: linking demography and population dynamics. Am Nat 153:476-491

Loeschcke V, Hoffmann AA (2007) Consequences of heat hardening on a field fitness component in Drosophila depend on environmental temperature. Am Nat 169:175-183

Lynch M, Gabriel W (1987) Environmental tolerance. Am Nat 129:283-303

Mahlman JD (1998) Science and non-science concerning human-caused global warming. Annu Rev Energy Environ 23:83-105

Marais E, Chown SL (2008) Beneficial acclimation and the Bogert effect. Ecol Lett 11:1027-1036

Marais E, Terblanche JS, Chown SL (2009) Life stage-related differences in hardening and acclimation of thermal tolerance traits in the kelp fly, Paractora dreuxi (Diptera. Helcomyzidae). J Insect Physiol $55: 336-343$

Masel J, King OD, Maughan H (2007) The loss of adaptive plasticity during long periods of environmental stasis. Am Nat 169:38-46

May RM (1986) The search for patterns in the balance of nature: advances and retreats. Ecology 67: 1115-1126

McGeoch MA, le Roux PC, Hugo EA et al (2006) Species and community responses to short-term climate manipulation: microarthropods in the sub-Antarctic. Austral Ecol 31:719-731

McPeek MA, Holt RD (1992) The evolution of dispersal in spatially and temporally varying environments. Am Nat 140:1010-1027

Millennium Ecosystem Assessment (2005) Ecosystems and human well-being: biodiversity synthesis. World Resources Institute, Washington, DC

Moran NA (1992) The evolutionary maintenance of alternative phenotypes. Am Nat 139:971-989

Moyle RG, Filardi CE, Smith CE et al (2009) Explosive Pleistocene diversification and hemispheric expansion of a great speciator. Proc Natl Acad Sci USA 106:1863-1868

O'Brien EM, Field R, Whittaker RJ (2000) Climatic gradients in woody plant (tree and shrub) diversity: water-energy dynamics, residual variation, and topography. Oikos 89:588-600

Orizaola G, Laurila A (2009) Microgeographic variation in temperature-induced plasticity in an isolated amphibian population. Evol Ecol. doi:10.1007/s10682-008-9285-x

Osovitz CJ, Hoffman GE (2007) Marine macrophysiology: studying physiological variation across large spatial scales in marine systems. Comp Biochem Physiol A 147:821-827

Overpeck JT, Cole JE (2006) Abrupt change in Earth's climate system. Annu Rev Environ Res 31:1-31

Parker BR, Vinebrooke RD, Schindler DW (2008) Recent climate extremes alter alpine lake ecosystems. Proc Natl Acad Sci USA 105:12927-12931 
Parmesan C (2006) Ecological and evolutionary responses to recent climate change. Annu Rev Ecol Evol Syst 37:637-669

Parmesan C, Yohe G (2003) A globally coherent fingerprint of climate change impacts across natural systems. Nature 421:37-42

Parvinen K, Dieckmann U, Gyllenberg M et al (2003) Evolution of dispersal in metapopulations with local density dependence and demographic stochasticity. J Evol Biol 16:143-153

Pelini SL, Dzurisin JDK, Prior KM et al (2009) Translocation experiments with butterflies reveal limits to enhancement of poleward populations under climate change. Proc Natl Acad Sci USA 106: $11160-11165$

Pimm S, Raven P, Peterson A et al (2006) Human impacts on the rates of recent, present, and future bird extinctions. Proc Natl Acad Sci USA 103:10941-10946

Porter WP (1989) New animal models and experiments for calculating growth potential at different elevations. Physiol Zool 62:286-313

Porter WP, Budaraju S, Stewart WE et al (2000) Calculating climate effects on birds and mammals: impacts on biodiversity, conservation, population parameters, and global community structure. Am Zool 40:597-630

Pörtner HO (2002) Climate variations and the physiological basis of temperature dependent biogeography: systemic to molecular hierarchy of thermal tolerance in animals. Comp Biochem Physiol A 132: 739-761

Pörtner HO, Knust R (2007) Climate change affects marine fishes through the oxygen limitation of thermal tolerance. Science 315:95-97

Pounds JA, Fogden MPL, Campbell JH (1999) Biological response to climate change on a tropical mountain. Nature 398:611-615

Pounds JA, Bustamante MR, Coloma LA et al (2006) Widespread amphibian extinctions from epidemic disease driven by global warming. Nature 439:161-167

Pulido F (2007) Phenotypic changes in spring arrival: evolution, phenotypic plasticity, effects of weather and condition. Clim Res 35:5-23

Pulido F, Berthold P (2004) Microevolutionary response to climate change. Adv Ecol Res 35:151-183

Régnìere J, Bentz B (2007) Modeling cold tolerance in the mountain pine beetle, Dendroctonus ponderosae. J Insect Physiol 53:559-572

Relyea RA (2002) Costs of phenotypic plasticity. Am Nat 159:272-282

Ricklefs R (2008) Disintegration of the ecological community. Am Nat 172:741-750

Rohr JR, Raffel TR, Romansic JM et al (2008) Evaluating the links between climate, disease spread, and amphibian declines. Proc Natl Acad Sci USA 105:17436-17441

Root TL, Price JT, Hall KR et al (2003) Fingerprints of global warming on wild animals and plants. Nature 421:57-60

Rosenzweig C, Karoly D, Vicarelli M et al (2008) Attributing physical and biological impacts to anthropogenic climate change. Nature 453:353-357

Rovito SM, Parra-Olea G, Vásquez-Almazán CR et al (2009) Dramatic declines in Neotropical salamander populations are an important part of the global amphibian crisis. Proc Natl Acad Sci USA 106: 3231-3236

Sibly RM, Calow P (1986) Physiological ecology of animals. An evolutionary approach. Blackwell Scientific Publications, Oxford

Simberloff D (2004) Community ecology: is it time to move on? Am Nat 163:787-799

Simmons AD, Thomas CD (2004) Changes in dispersal during species' range expansions. Am Nat 164: 378-395

Šizling AL, Šizlingová E, Storch D et al (2009) Rarity, commonness and the contribution of individual species to species richness patterns. Am Nat 174:82-93

Soberón J (2007) Grinnellian and Eltonian niches and geographic distributions of species. Ecol Lett 10:1115-1123

Stachowicz JJ, Terwin JR, Whitlatch RB et al (2002) Linking climate change and biological invasions: ocean warming facilitates nonindigenous species invasions. Proc Natl Acad Sci USA 99:15497-15500

Staley JT, Mortimer SR, Masters GJ et al (2006) Drought stress differentially affects leaf-mining species Ecol Entomol 31:460-469

Stern N (2007) The economics of climate change. The Stern review. Cambridge University Press, Cambridge

Stige LC, Stave J, Chan K-S et al (2006) The effect of climate variation on agro-pastoral production in Africa. Proc Natl Acad Sci USA 103:3049-3053

Stillman JH (2003) Acclimation capacity underlies susceptibility to climate change. Science 301:65 
Storch D, Sizling AL, Reif J et al (2008) The quest for a null model for macroecological patters: geometry of species distributions at multiple spatial scales. Ecol Lett 11:771-784

Sultan SE, Spencer HG (2002) Metapopulation structure favors plasticity over local adaptation. Am Nat 160:271-283

Tauber MJ, Tauber CA, Nyrop JP et al (1998) Moisture, a vital but neglected factor in the seasonal ecology of insects: hypotheses and tests of mechanisms. Environ Entomol 27:523-530

Theoharides KA, Dukes JS (2007) Plant invasion across space and time: factors affecting nonindigenous species success during four stages of invasion. New Phytol 176:256-273

Thomas CD, Bodsworth EJ, Wilson RJ et al (2001) Ecological and evolutionary processes at expanding range margins. Nature 411:577-581

Thomas CD, Cameron A, Green RE et al (2004) Extinction risk from climate change. Nature 427:145-148

Thomas CD, Franco AMA, Hill JK (2006) Range retractions and extinction in the face of climate warming. Trends Ecol Evol 21:415-416

Thomas CD, Bulman CR, Wilson RJ (2008) Where within a geographical range do species survive best? A matter of scale. Insect Conserv Divers 1:2-8

Thuiller W, Albert C, Araújo MB et al (2008) Predicting global change impacts on plant species' distributions: future challenges. Perspect Plant Ecol Evol Syst 9:137-152

Tolley KA, Davies SJ, Chown SL (2008) Deconstructing a controversial local range expansion: conservation biogeography of the painted reed frog (Hyperolius marmoratus) in South Africa. Divers Distrib $14: 400-411$

Tufto J (2000) The evolution of plasticity and nonplastic spatial and temporal adaptations in the presence of imperfect environmental cues. Am Nat 156:121-130

Turner J, Overland JE, Walsh JE (2007) An Arctic and Antarctic perspective on recent climate change. Int J Climatol 27:277-293

Tylianakis JM, Didham RK, Baccompte J et al (2008) Global change and species interactions in terrestrial ecosystems. Ecol Lett 11:1351-1363

van Kleunen M, Fischer M (2005) Constraints on the evolution of adaptive phenotypic plasticity in plants. New Phytol 166:49-60

van Kleunen M, Fischer M (2007) Commentary: progress in the detection of costs of phenotypic plasticity in plants. New Phytol 176:727-730

van Tienderen P (1991) Evolution of generalists and specialists in spatially heterogeneous environments. Evolution 45:1317-1331

Walther G-R, Post E, Convey P et al (2002) Ecological responses to recent climate change. Nature 416: 389-395

Walther G-R, Berger S, Sykes MT (2005) An ecological 'footprint' of climate change. Proc R Soc Lond B 272:1427-1432

Welbergen JA, Klose SM, Markus N, Eby P (2008) Climate change and the effects of temperature extremes on Australian flying foxes. Proc R Soc Lond B 275:419-425

Whisler FD, Acock B, Baker DN et al (1986) Crop simulation models in agronomic systems. Adv Agron 40:141-208

Wiens JJ, Graham CH (2005) Niche conservatism: integrating evolution, ecology, and conservation biology. Annu Rev Ecol Evol Syst 36:519-539

Wikelski M, Spinney L, Schelsky W et al (2003) Slow pace of life in tropical sedentary birds: a commongarden experiment on four stonechat populations from different latitudes. Proc R Soc Lond B 270:2383-2388

Worthen WB, Jones MT, Jetton RM (1998) Community structure and environmental stress: desiccation promotes nestedness in mycophagous fly communities. Oikos 81:45-54 